\title{
Dorfman-Chanarin Syndrome: A Rare Cause of Metabolic Associated Fatty Liver Disease Related to Homozygosity of the Nonsense Mutation c.934C >T (p.R312*)
}

\author{
Rita Quelhas da Costa ${ }^{a}$ Francisco Laranjeira $^{b}$ Isaura Duarte Ribeiro ${ }^{b, c}$ \\ António Filipe Santos $^{d}$ Filipe Nery ${ }^{\mathrm{e}-\mathrm{g}}$

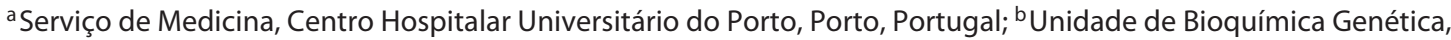 \\ Centro de Genética Médica Doutor Jacinto Magalhães, Centro Hospitalar Universitário do Porto, Porto, Portugal; \\ 'Unidade Multidisciplinar de Investigação Biomédica, Instituto de Ciências Biomédicas Abel Salazar, Universidade \\ do Porto, Porto, Portugal; ' 'Serviço de Hematologia Laboratorial, Centro Hospitalar Universitário do Porto, Porto, \\ Portugal; ' Serviço de Cuidados Intensivos - Unidade de Cuidados Intermédios Médico-Cirúrgica, Centro Hospitalar \\ Universitário do Porto, Porto, Portugal; ${ }^{\mathrm{f} E p i U n i t, ~ I n s t i t u t o ~ d e ~ S a u ́ d e ~ P u ́ b l i c a ~ d a ~ U n i v e r s i d a d e ~ d o ~ P o r t o, ~ P o r t o, ~}$ \\ Portugal; 9 Instituto de Ciências Biomédicas de Abel Salazar, Universidade do Porto, Porto, Portugal
}

\section{Keywords}

Dorfman-Chanarin syndrome $\cdot$ Inborn errors of metabolism · Metabolic associated fatty liver disease $\cdot$ Liver transplantation

\section{Abstract}

Metabolic associated fatty liver disease became the most common form of chronic liver disease, in the vast majority of the cases related to increased insulin resistance or metabolic dysregulation. Yet, other causes may be implied. We report the late diagnosis of Dorfman-Chanarin syndrome in a nonalcoholic steatohepatitis previously labeled cirrhotic middle-aged man, with consanguineous parents, complicated with hepatocellular carcinoma. Congenital ichthyosis, neurosensory hearing loss and elevated muscular enzymes hit on the track of Dorfman-Chanarin syndrome. The genetic analysis uncovered a first-time described homozygotic nonsense mutation in the ABHD5 gene, responsible for coding the ABHD5 protein. The patient was successfully submitted to liver transplantation. Inborn errors of metabolism are a rare cause of metabolic associated fatty liver disease, but they need to be kept in consideration in all patients who present with atypical clinical features. This shall raise the awareness of physicians to rare forms of presentation since it may imply not only a different prognosis, but also other actions, like particular therapies as liver transplantation due to related complications of cirrhosis, or familial screening.

(C) 2021 Sociedade Portuguesa de Gastrenterologia Published by S. Karger AG, Basel

\section{Síndrome de Dorfman-Chanarin: uma causa rara de doença hepática gorda dismetabólica associada a homozigotia da mutação nonsense c.934C > T (p.R312*)}

\section{Palavras Chave}

Síndrome de Dorfman-Chanarin - Erros do metabolismo . Fígado gordo · Transplante hepático

\section{(c) 2021 Sociedade Portuguesa de Gastrenterologia} Published by S. Karger AG, Basel

This is an Open Access article licensed under the Creative Commons Attribution-NonCommercial-4.0 International License (CC BY-NC) (http://www.karger.com/Services/OpenAccessLicense), applicable to the online version of the article only. Usage and distribution for commercial purposes requires written permission.
Correspondence to:

Filipe Nery, filipegaionery@ gmail.com 


\section{Resumo}

A doença hepática gorda dismetabólica tornou-se a forma mais comum de doença hepática crónica, estando mais vezes relacionada com o aumento da insulinorresistência ou desregulação metabólica. Contudo, outras causas podem estar também implicadas. Apresentamos o caso clínico de um doente com um diagnóstico de síndrome de Dorfman-Chanarin estabelecido tardiamente num homem de meia-idade com um diagnóstico prévio de cirrose associada a esteatohepatite não alcoólica, com pais consanguíneos, e complicada de carcinoma hepatocelular. A presença de ictiose congénita, a perda de audição neurosensorial, e a elevação de enzimas musculares, colocaram na pista de diagnóstico de síndrome de Dorfman-Chanarin. O estudo genético demonstrou a presença de uma mutação nonsense descrita pela primeira vez em homozigotia no gene $A B H D 5$, responsável pela codificação da proteína ABHD5. O doente foi submetido a transplante hepático com sucesso. Os erros inatos do metabolismo são uma causa rara de doença hepática gorda, mas necessitam de ser tidos em consideração em todos os doentes que se apresentem com características clínicas atípicas. Isto deve aumentar a consciencialização dos médicos para formas raras de apresentação, uma vez que pode implicar não apenas um prognóstico diferente, mas também outras ações, como o transplante hepático por complicações associadas à cirrose, ou despiste familiar.

(C) 2021 Sociedade Portuguesa de Gastrenterologia Publicado por S. Karger AG, Basel

\section{Introduction}

Metabolic associated fatty liver disease (MAFLD) is now considered the most prevalent chronic liver disease, affecting a quarter of the world population and up to $46 \%$ of the Western adult population $[1,2]$. It is characterized by an excessive liver fat accumulation (steatosis in more than $5 \%$ of the hepatocytes), as a result of insulin resistance on hepatic metabolism [2]. MAFLD can also result, in a minority of cases, from other causes unrelated to insulin resistance, as inborn metabolic diseases [3]. The spectrum of presentation of MAFLD is wide ranging, from simple steatosis to steatohepatitis and related fibrosis, cirrhosis, and its complications [2].

Dorfman-Chanarin syndrome (DCS; Online Mendelian Inheritance in Man [OMIM] 275630) is a rare multisystemic autosomal recessive inborn metabolic disease, first described by Dorfman et al. [4] in 1974 and Chanarin et al. [5] in 1975. DCS is a consequence of mutations in the protein alpha/beta-hydrolase domain-containing protein 5 (ABHD5), which acts as a cofactor for adipose triglyceride lipase (ATGL) [6]. ABHD5 has also been shown to act as a lysophosphatidic acid acyltransferase [7]. This entity also presents commonly with milder muscular disease and with congenital ichthyosis. As both entities may share some particular liver histological findings, a rare entity as DCS may be easily misdiagnosed as MAFLD related to insulin resistance.

We herein present a patient with a diagnosis of DCS established almost 3 decades after a first diagnosis of MAFLD, who has been successfully submitted to liver transplantation.

\section{Case Description}

A 61-year-old Caucasian male with a long-established diagnosis of non-alcoholic steatohepatitis/MAFLD related cirrhosis was referred to the liver transplantation outpatient clinic in 2016 due to suspicion of hepatocellular carcinoma. Back to 1986, while having mild alcohol consumption and a body mass index of 26.6, he was diagnosed with fatty liver disease based on histological findings. Alcohol consumption was stopped by that time. In 2014, he was diagnosed with liver cirrhosis. Another percutaneous liver biopsy was done, documenting a cirrhotic liver with signs of macrovesicular steatosis, necroinflammatory lesions and ballooning degeneration of hepatocytes, compatible with MAFLD. The follow-up of the patient included a 6-month ultrasound screening of hepatocellular carcinoma and, in this context, he was referred to our institution, to be evaluated for liver transplantation.

A "scaly" rash most evident on his trunk since birth and hearing loss since the 1980s, for which he had had surgery 16 years later, were documented. Neither blood transfusions nor intravenous drugs use were reported. No other cardiovascular risk factors besides a recently diagnosed arterial hypertension and a body mass index in the overweight category (29.8) were perceived. Concerning his family history, he was born of a consanguineous marriage between two first cousins. Thyroid disease is prevalent in his family, but no one else had history of liver disease, abnormal skin rashes, nor progressive deafness at a young age, although two of his siblings complained of tinnitus. None of his four brothers and sisters shared clinical features compatible with DCS. On physical examination, he had a good overall appearance. His skin was dry and scaly (fish scale-like; Fig. 1), especially on the trunk, hard to fold; a Dermatology consultant confirmed ichthyosis. His abdomen did not show any signs of collateral circulation and his liver was palpable $2 \mathrm{~cm}$ below the rib cage; neither splenomegaly nor ascites were identified. He presented with a Model for End-stage Liver Disease score of 9 and a Child-Pugh score of 5 points (class A). Alpha-fetoprotein was within the normal range $(1.9 \mu \mathrm{g} / \mathrm{L})$. Liver analytical profile revealed aspartate transaminase (AST) $101 \mathrm{U} / \mathrm{L}$, alanine transaminase (ALT) $109 \mathrm{U} / \mathrm{L}$, total bilirubin $1.56 \mathrm{mg} / \mathrm{dL}$, alkaline phosphatase (ALP) $130 \mathrm{U} / \mathrm{L}, \gamma$-glutamyltransferase (GGT) 270 U/L. Lipid profile was normal. A raised creatine kinase (CK) 


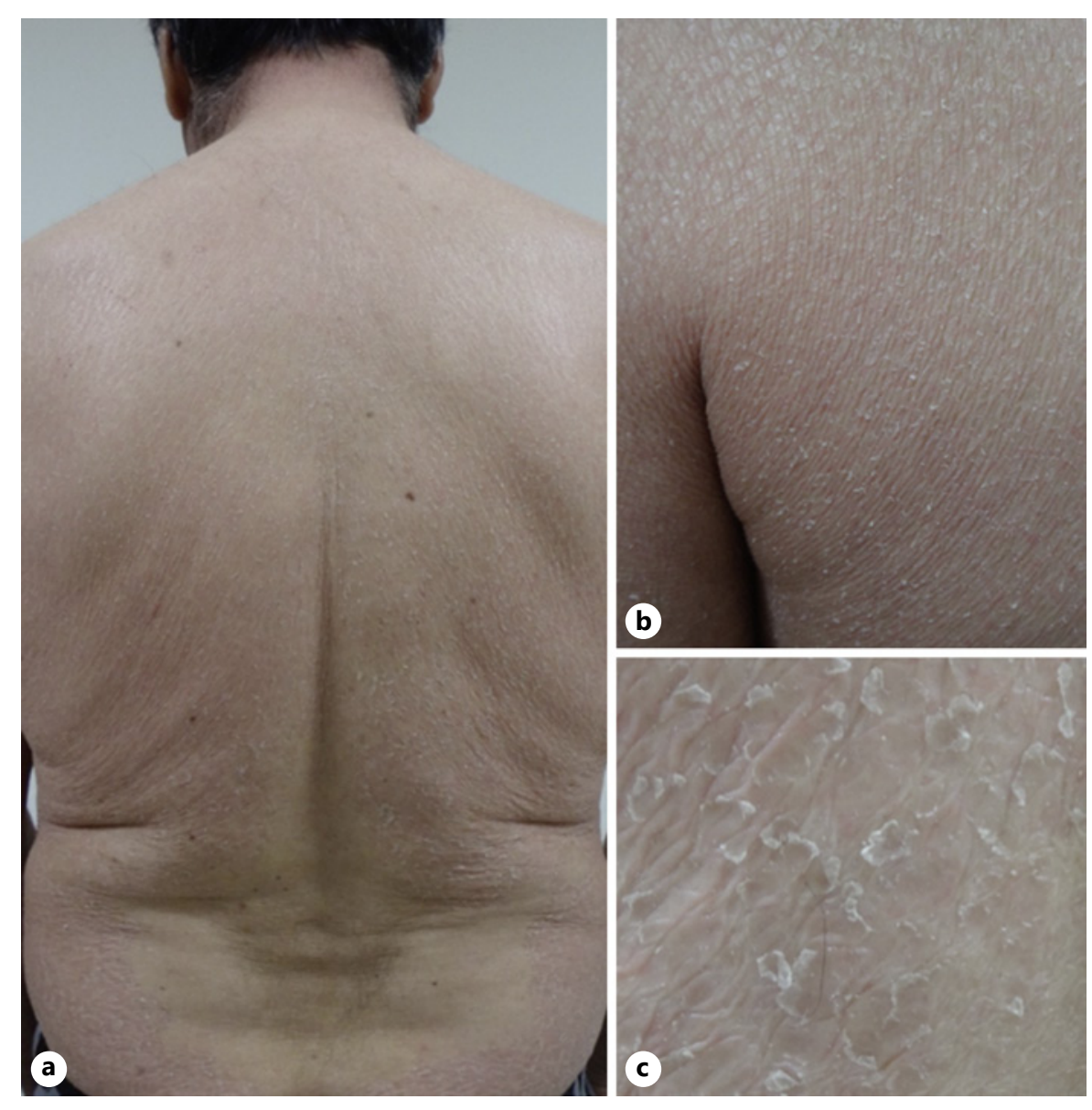
fish scale-like appearance (c).
Fig. 1. Skin ichthyosis (a, b). Details of the

ent homozygosity. Since both of his parents were deceased, their genetic study was unavailable, but the hypothesis of "true" homozygosity was considered very likely because of their consanguinity. Therefore, the patient was labeled as a homozygous for this particular mutation, which confirmed the proposed diagnosis.

The patient was started on ursodeoxycholic acid, which slightly improved his biochemical profile (AST $62 \mathrm{U} / \mathrm{L}$, ALT $57 \mathrm{U} / \mathrm{L}$, ALP $101 \mathrm{U} / \mathrm{L}$, GGT $60 \mathrm{U} / \mathrm{L}$, total bilirubin $1.56 \mathrm{mg} / \mathrm{dL}$ ). Large esophageal and gastric varices were found on his last upper endoscopy and non-selective beta-blockers were started. Abdominal magnetic resonance found a $17-\mathrm{mm}$ nodule between segments IV and VIII, suggestive of hepatocellular carcinoma, treated with microwave thermal ablation. The patient was successfully submitted to liver transplant in January 2019 and remains, to date, with a completely normal liver profile and no signs of hepatocellular carcinoma relapse. rounding zones, using the software PrimerBlast (www.ncbi.nlm. nih.gov/tools/primer-blast/). The PCR products were purified by the illustra ${ }^{\mathrm{TM}}$ ExoProStar $^{\mathrm{TM}}$ (GE Healthcare Life Sciences) and used for direct sequencing with BigDye ${ }^{\mathrm{TM}}$ Terminator version 3.1 Cycle Sequencing Kit (Thermo Fisher Scientific) and ran on ABI PRISM ${ }^{\circledR}$ 3100 Genetic Analyzer (Applied Biosystems). All the obtained sequences were compared with the reference sequence (NM_016006.4), using the SeqScape ${ }^{\circledR}$ Software version 2.5 (Applied Biosystems). A nonsense mutation c.934C >T (p.R312*), first described by Pujol et al. [8] in 2005, was found in exon 6, in appar-

\section{Discussion}

Histological compatible MAFLD features have a multitude of etiologies, so when the most common causes are excluded and other non-explained clinical findings are 
Fig. 2. Jordans' anomaly in a neutrophil (a), an eosinophil (b), and a monocyte (c; peripheral blood smear stained in Leishman's stain, $\times 1,000)$. Lipid vacuoles were confirmed by using oil red staining $(\times 1,000$; d).
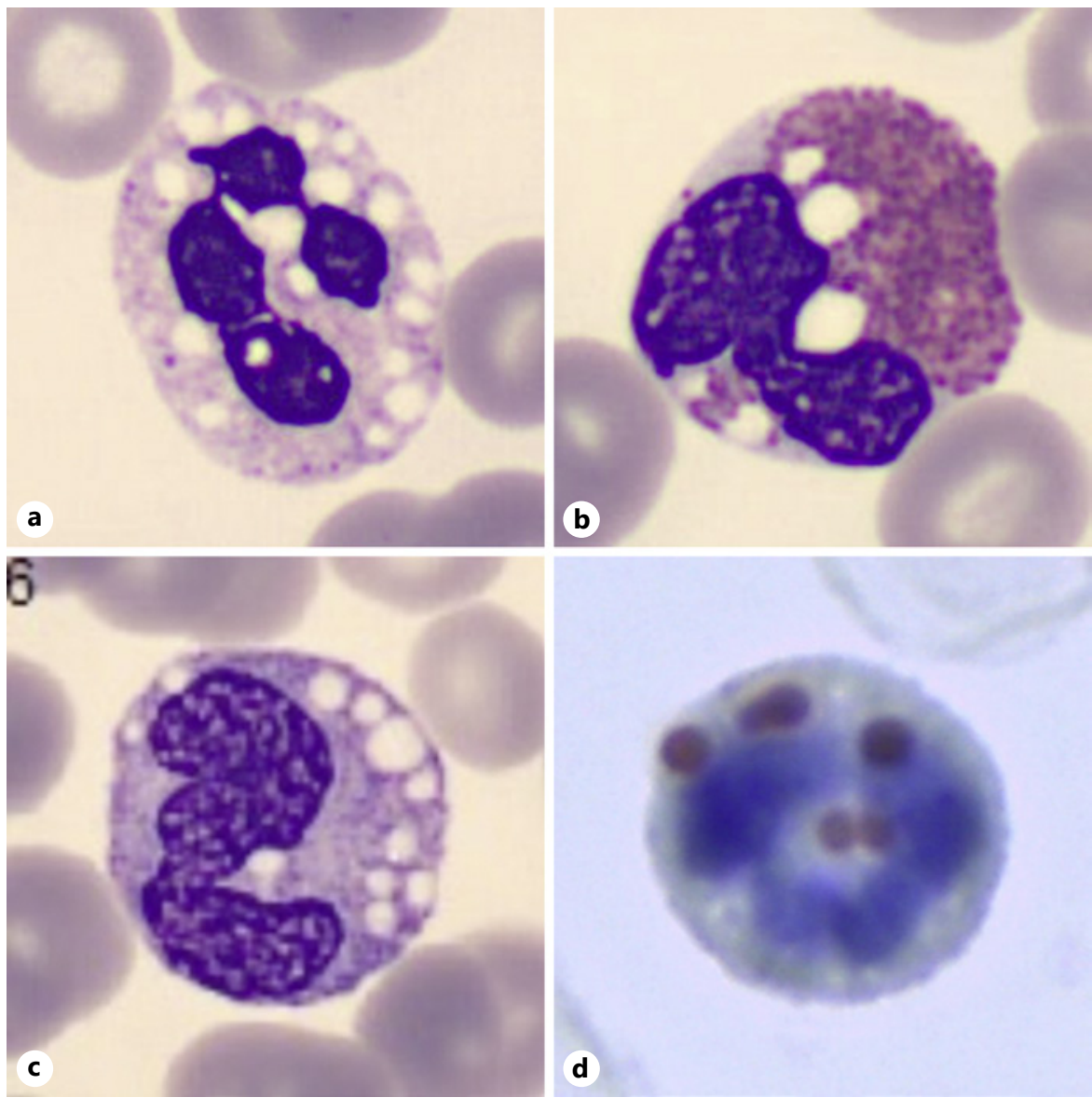

observed, rare causes should be looked for. Here we present a case of a rare cause of histological findings compatible with MAFLD, but without any other clinical features besides overweight and a recently diagnosed systemic arterial hypertension. Importantly, diagnosis of DCS remained unnoticed till significant findings in the clinical past history and physical examination were considered, and whose clinical course and evolution culminated in the diagnosis of hepatocellular carcinoma that led to liver transplantation.

The ABHD5 gene (MIM*604780) is located on chromosome 3p21 and is comprised of seven exons that encompass about $28 \mathrm{~kb}$ of genomic DNA, generating a 349-amino acid protein (ABHD5). This enzyme serves as a cofactor for ATGL, enhancing its enzymatic activity up to twenty-fold; when a mutation alters the amino acid sequence of this protein, the intracellular accumulation of triglycerides ensues, causing DCS. Less than one hundred cases have been reported worldwide, with the majority of them coming from Mediterranean and Middle-East countries, especially Turkey. The first report on the sequence analysis of the ABHD5 protein in DCS patients [9] documented eight distinct mutations; the spectrum of gene variants included insertion, deletion, splice-site and point mutations. Since then, more variants have been described, most of them involving truncation mutations in ABHD5, but large deletions were also found [10].

As far as we know, this is the first known case of homozygosity of the nonsense mutation c.934C $>\mathrm{T}$ ( $\mathrm{p}$. R312*), first described in 2005 in a 4-year-old compound heterozygote [8]. This nonsense mutation in exon 6 , inherited from the patient's consanguineous parents, led to the replacement of arginine for a stop codon, originating a truncated 312-amino acid protein. Although our patient's diagnosis was made several years later than most of the published reports [11-14], we do not have enough information regarding his past medical history to be able to consider any causative relation between this mutation and his clinical phenotype. In fact, several authors have reported conflicting evidence regarding a genotype-phe- 
notype correlation [10,15-17]. Redaelli et al. [10] identified a mutation that conserved $>90 \%$ of the native protein, but was associated with severe clinical manifestations, and also a mutation that caused precocious truncation of the protein, which was associated with severe steatohepatitis, but a relatively mild phenotype concerning other clinical DCS features. The authors hypothesized that the accumulation of non-functional ABHD5 proteins may have a more deleterious consequence for cellular lipid droplets metabolism in some tissues than total loss of the protein expression [10].

$A B H D 5$ is expressed in multiple tissues (including skin, muscle, liver, gastrointestinal epithelium, central nervous system, and blood leukocytes), thus explaining the multisystemic but also very heterogeneous manifestations associated with DCS. The most frequent and characteristic features are ichthyosis, liver steatosis/hepatomegaly, and mild myopathy, but ataxia, neurosensory hearing loss, sub-capsular cataracts, nystagmus, strabismus, mental retardation, short stature, microcephaly, and intestinal and renal involvement have also been described $[4,5,18-22]$. Our patient presented with MAFLD histological features (which evolved into liver cirrhosis with portal hypertension and hepatocellular carcinoma), ichthyosis, altered muscle enzymes, and unilateral neurosensory hearing loss at different stages of his life, which, altogether, suggest a typical DCS presentation.

Liver involvement is present in about $64 \%$ of patients with DCS [21], but the severity of steatohepatitis is variable, with cirrhosis being present in approximately $15 \%$ of patients [13, 23-25]. Our patient was first diagnosed with chronic liver disease back in 1986 with MAFLD histological features, while clinical findings compatible with cirrhosis only showed up more than 28 years later. There are cases of presentation with cirrhosis both in children [23-26] as in adults $[12,13,27]$, but no correlation between genotype and phenotype has been uncovered. While not resolving or improving other manifestations of DCS, liver transplantation has been performed in an adult with this syndrome, with no relapse of steatosis or fibrosis in the control liver biopsy performed at 1 year of follow-up [28]. Our patient was successfully transplanted due to hepatocellular carcinoma that developed in an already cirrhotic liver after a bridging therapy with microwave thermal ablation in January 2019. One year and a half later, he presents a completely normal liver profile and no signs of hepatocellular carcinoma relapse. In the absence of an abnormal liver profile, no liver biopsy of the explant was performed to date.

Cutaneous involvement in DCS is a constant feature and ichthyosis usually corresponds to non-bullous con- genital ichthyosiform erythroderma [20], as observed in our patient, but other dermatologic manifestations have been reported $[4,8,21]$. Nevertheless, there is no correlation between the severity of the skin condition and the microscopic findings [20], which is supported by ABHD5's ATGL-independent role in epidermal lipid metabolism $[29,30]$. A mild myopathy was suspected because of elevated CK, but we did not perform a muscle biopsy to confirm. In DCS, opposite to neutral lipid storage disease with myopathy, there is no cardiomyopathy simultaneous to skeletal muscle disease, presumably because even a low amount of lipase activity may preserve cardiac function [31]. This issue is important when considering evaluation of patients to liver transplantation. Our patient also had unilateral neurosensorial deafness, but no other symptoms or signs of nervous system, intestinal, or renal involvement.

The most common and characteristic laboratory finding is May-Grünwald-Giemsa-negative lipid droplets (Jordans' anomaly) in otherwise normal peripheral blood leukocytes [18], which was seen in our patient (Fig. 2). Before a clinical suspicion of DCS, a blood smear for screening for lipid inclusions in neutrophils must be made. Muscular and liver enzymes can be mild to moderately elevated (two- to three-fold), consequent to muscle and liver involvement, but serum lipids, as most of the other common biochemical blood tests, are usually normal [9]. Our patient presented with abnormal liver tests, as expected, and with CK elevation, possibly predicting some skeletal muscle involvement.

There is no standardized treatment for DCS. Restriction of long chain fatty acids in the diet and promoting middle chain fatty acid intake are supposed to benefit the skin by reducing ichthyosis and alter the lipid accumulation in other organs, but no randomized controlled trials have been done. Acitretin showed a beneficial effect in reducing ichthyosis in two infants, even in the presence of compromised liver function [32,33], but there are no studies regarding the long-term effect on DCS patients. Ursodeoxycholic acid has been investigated in several randomized controlled trials for MAFLD, at different doses and for up to 2 years, but only showed some biochemical but no histological improvements [34-36]; the improvement on our patient's laboratory data also demonstrated this effect.

DCS is a rare congenital disorder with overlapping liver histological features with MAFLD, which may lead to misdiagnosis. Evolution of the chronic liver disease related to DCS does not reflect the type of mutation nor is it predictive of the outcome. Yet, once cirrhosis is estab- 
lished, common complications including hepatocellular carcinoma may arise and whose conduct is similar to that of cirrhosis of other etiologies. In this setting, liver transplantation may be successfully performed and indications are the same as for patients with other etiologies of liver disease, as it may resolve cirrhosis complications but not extrahepatic manifestations of DCS.

\section{Acknowledgement}

The authors would like to thank Dr. José Ramón Vizcaíno for all the cooperation in the study of the peripheral blood smear.

\section{Statement of Ethics}

The patient's written informed consent was obtained and is in the possession of the authors.

\section{Conflict of Interest Statement}

The authors declare that there are no conflicts of interest or any other nonfinancial relationships that may influence the writing of the manuscript.

\section{Funding Sources}

The authors received no funding for the current case report.

\section{Author Contributions}

R.Q.C. and F.N. were responsible for drafting the manuscript and provided critical revision for important intellectual content. All the authors have been implicated either in the diagnosis and/ or clinical management of the patient. All the authors revised the manuscript for final version approval.

\section{References}

1 Eslam M, Newsome PN, Sarin SK, Anstee QM, Targher G, Romero-Gomez M, et al. A new definition for metabolic dysfunction-associated fatty liver disease: an international expert consensus statement. J Hepatol. 2020 Jul;73(1):202-9.

2 European Association for the Study of the Liver (EASL), European Association for the Study of Diabetes (EASD), European Association for the Study of Obesity (EASO). EASLEASD-EASO Clinical Practice Guidelines for the management of non-alcoholic fatty liver disease. J Hepatol. 2016 Jun;64(6):1388-402.

3 Kneeman JM, Misdraji J, Corey KE. Secondary causes of nonalcoholic fatty liver disease. Therap Adv Gastroenterol. 2012 May;5(3): 199-207.

4 Dorfman ML, Hershko C, Eisenberg S, Sagher F. Ichthyosiform dermatosis with systemic lipidosis. Arch Dermatol. 1974 Aug;110(2):261-6.

5 Chanarin I, Patel A, Slavin G, Wills EJ, Andrews TM, Stewart G. Neutral-lipid storage disease: a new disorder of lipid metabolism. BMJ. 1975 Mar;1(5957):553-5.

6 Lass A, Zimmermann R, Haemmerle G, Riederer M, Schoiswohl G, Schweiger M, et al. Adipose triglyceride lipase-mediated lipolysis of cellular fat stores is activated by CGI-58 and defective in Chanarin-Dorfman Syndrome. Cell Metab. 2006 May;3(5):309-19.

7 Ghosh AK, Ramakrishnan G, Chandramohan C, Rajasekharan R. CGI-58, the causative gene for Chanarin-Dorfman syndrome, mediates acylation of lysophosphatidic acid. J Biol Chem. 2008 Sep;283(36):24525-33.

8 Pujol RM, Gilaberte M, Toll A, Florensa L, Lloreta J, González-Enseñat MA, et al. Erythrokeratoderma variabilis-like ichthyosis in
Chanarin-Dorfman syndrome. Br J Dermatol. 2005 Oct;153(4):838-41.

9 Lefèvre C, Jobard F, Caux F, Bouadjar B, Karaduman A, Heilig R, et al. Mutations in CGI-58, the gene encoding a new protein of the esterase/lipase/thioesterase subfamily, in Chanarin-Dorfman syndrome. Am J Hum Genet. 2001 Nov;69(5):1002-12.

10 Redaelli C, Coleman RA, Moro L, DacouVoutetakis C, Elsayed SM, Prati D, et al. Clinical and genetic characterization of ChanarinDorfman syndrome patients: first report of large deletions in the ABHD5 gene. Orphanet J Rare Dis. 2010 Dec;5(1):33.

11 Schleinitz N, Fischer J, Sanchez A, Veit V, Harle JR, Pelissier JF. Two new mutations of the ABHD5 gene in a new adult case of Chanarin Dorfman syndrome: an uncommon lipid storage disease. Arch Dermatol. 2005 Jun;141(6):798-800.

12 Ciesek S, Hadem J, Fischer J, Manns MP, Strassburg CP. A rare cause of nonalcoholic fatty liver disease. Ann Intern Med. 2006 Jul;145(2):154-5.

13 Ronchetti A, Prati D, Pezzotta MG, Tavian D, Colombo R, Callea F, et al. Severe steatohepatitis in a patient with a rare neutral lipid storage disorder due to ABHD5 mutation. J Hepatol. 2008 Sep;49(3):474-7.

14 Gomez-Moyano E, Godoy-Diaz DJ, PonceVerdugo L, Sanz-Trelles A, Vera-Casaño A, Sierra-Salinas C. Chanarin-Dorfman syndrome in three siblings in a non-consanguineous family. J Eur Acad Dermatol Venereol. 2016 Jan;30(1):157-9.

15 Aggarwal S, Maras JS, Alam S, Khanna R, Gupta SK, Ahuja A. Novel nonsense mutation of ABHD5 in Dorfman-Chanarin syndrome with unusual findings: a challenge for genotype-phenotype correlation. Eur J Med Genet. 2012 Mar;55(3):173-7.

16 Nur BG, Gencpinar P, Yuzbasioglu A, Emre SD, Mihci E. Chanarin-Dorfman syndrome: Genotype-Phenotype Correlation. Eur J Med Genet. 2015 Apr;58(4):238-42.

17 Takeichi T, Sugiura K, Tso S, Simpson MA, McGrath JA, Akiyama M. Bi-allelic nonsense mutations inABHD5 underlie a mild phenotype of Dorfman-Chanarin syndrome. J Dermatol Sci. 2016 Feb;81(2):134-6.

18 Williams ML, Koch TK, O’Donnell JJ, Frost PH, Epstein LB, Grizzard WS, et al. Ichthyosis and neutral lipid storage disease. Am J Med Genet. 1985 Apr;20(4):711-26.

19 Igal RA, Rhoads JM, Coleman RA. Neutral lipid storage disease with fatty liver and cholestasis. J Pediatr Gastroenterol Nutr. 1997 Nov;25(5):541-7.

20 Srebrnik A, Brenner S, Ilie B, Messer G. Dorfman-Chanarin syndrome: morphologic studies and presentation of new cases. Am J Dermatopathol. 1998 Feb;20(1):79-85.

21 Peña-Penabad C, Almagro M, Martínez W, García-Silva J, Del Pozo J, Yebra MT, et al. Dorfman-Chanarin syndrome (neutral lipid storage disease): new clinical features. $\mathrm{Br} \mathrm{J}$ Dermatol. 2001 Feb;144(2):430-2.

22 Verma SB, Mittal A, Wollina U, Eckstein GH, Gohel K, Giehl K. Chanarin-Dorfman syndrome with rare renal involvement. Br J Dermatol. 2017 Feb;176(2):545-8.

23 Srinivasan R, Hadzić N, Fischer J, Knisely AS. Steatohepatitis and unsuspected micronodular cirrhosis in Dorfman-Chanarin syndrome with documented ABHD5 mutation. J Pediatr. 2004 May;144(5):662-5. 
24 Gupta P, Dhingra KK, Kawatra V, Singh T, Yadav S. Dorfman-Chanarin syndrome with cirrhosis. Pathology. 2008 Oct;40(6):650-3.

25 Cakir M, Bruno C, Cansu A, Cobanoglu U, Erduran E. Liver cirrhosis in an infant with Chanarin-Dorfman syndrome caused by a novel splice-site mutation in ABHD5. Acta Paediatr. 2010 Oct;99(10):1592-4.

26 Mitra S, Samanta M, Sarkar M, Chatterjee S. Dorfman-Chanarin syndrome: a rare neutral lipid storage disease. Indian J Pathol Microbiol. 2010 Oct-Dec;53(4):799-801.

27 Cakmak E, Alagozlu H, Yonem O, Ataseven $\mathrm{H}$, Citli S, Ozer H. Steatohepatitis and liver cirrhosis in Chanarin-Dorfman syndrome with a new ABDH5 mutation. Clin Res Hepatol Gastroenterol. 2012 Apr;36(2):e34-7.

28 Takeda K, Tanaka K, Kumamoto T, Morioka D, Endo I, Togo S, et al. Living donor liver transplantation for Dorfman-Chanarin syndrome with 1 year follow-up: case report. Transplant Proc. 2010 Nov;42(9):3858-61.
29 Radner FP, Streith IE, Schoiswohl G, Schweiger $M$, Kumari $M$, Eichmann TO, et al. Growth retardation, impaired triacylglycerol catabolism, hepatic steatosis, and lethal skin barrier defect in mice lacking comparative gene identification-58 (CGI-58). J Biol Chem. 2010 Mar;285(10):7300-11.

30 Uchida Y, Cho Y, Moradian S, Kim J, Nakajima K, Crumrine D, et al. Neutral lipid storage leads to acylceramide deficiency, likely contributing to the pathogenesis of DorfmanChanarin syndrome. J Invest Dermatol. 2010 Oct;130(10):2497-9.

31 Tavian D, Missaglia S, Redaelli C, Pennisi EM, Invernici G, Wessalowski R, et al. Contribution of novel ATGL missense mutations to the clinical phenotype of NLSD-M: a strikingly low amount of lipase activity may preserve cardiac function. Hum Mol Genet. 2012 Dec;21(24):5318-28.

32 Israeli S, Pessach Y, Sarig O, Goldberg I, Sprecher E. Beneficial effect of acitretin in Chanarin-Dorfman syndrome. Clin Exp Dermatol. 2012 Jan;37(1):31-3.
33 Srinivasaraghavan R, Krishnamurthy S, Chandar R, Cassandrini D, Mahadevan S, Bruno C, et al. Acitretin-responsive ichthyosis in Chanarin-Dorfman syndrome with a novel mutation in the ABHD5/CGI-58 gene. Pediatr Dermatol. 2014 Sep-Oct;31(5):612-4.

34 Lindor KD, Kowdley KV, Heathcote EJ, Harrison ME, Jorgensen R, Angulo P, et al. Ursodeoxycholic acid for treatment of nonalcoholic steatohepatitis: results of a randomized trial. Hepatology. 2004 Mar;39(3):770-8.

35 Dufour JF, Oneta CM, Gonvers JJ, Bihl F, Cerny A, Cereda JM, et al.; Swiss Association for the Study of the Liver. Randomized placebo-controlled trial of ursodeoxycholic acid with vitamin e in nonalcoholic steatohepatitis. Clin Gastroenterol Hepatol. 2006 Dec;4(12):1537-43.

36 Leuschner UF, Lindenthal B, Herrmann G, Arnold JC, Rössle M, Cordes HJ, et al.; NASH Study Group. High-dose ursodeoxycholic acid therapy for nonalcoholic steatohepatitis: a double-blind, randomized, placebo-controlled trial. Hepatology. 2010 Aug;52(2):472-9. 